\title{
Acetylcholinesterase Modified Porous Silicon for Electrochemical Measurement of Total Active Immobilized Enzyme Amount and Effective Malathion Detection
}

\author{
Khadidja Khaldi ${ }^{1,2 *}$, Sabrina $\operatorname{Sam}^{1}$, Noureddine Gabouze ${ }^{1}$ \\ ${ }^{1}$ Division Couches Minces Surface et Interfaces CMSI, Centre de Recherche en Technologie des Semi-conducteurs pour \\ l'Energétique CRTSE, 02 Bd. Frantz Fanon, BP 140, Alger-7 Merveilles, Algiers, Algeria \\ ${ }^{2}$ Centre de Recherche Scientifique et Technique en Analyses Physico-chimiques CRAPC, BP 384, Bou-Ismail, RP 42004, \\ Tipaza, Algeria
}

Corresponding Author Email: khadidjaphy@yahoo.fr

https://doi.org/10.18280/i2m.190107

Received: 23 October 2019

Accepted: 29 December 2019

\section{Keywords:}

biosensors, porous materials, amperometric, acetylcholinesterase, boron doped diamant

\begin{abstract}
An amperometric method to measure the total amount of active and inhibited immobilized Acetylcholinesterase enzyme (AChE) and the quantification of AChE inhibitors was realized. In this approach porous silicon (PSi) surface was used as a matrix for AChE immobilization and Boron doped polycrystalline diamant (BDPD) was used as working electrode for the electrochemical measurements. The covalent immobilization of AChE from electric eel was achieved on amine functionalized PSi surface previously decorated with Au particles. This surface is suitable for a stable attachment of AChE enzyme. The amperometric detection of $\mathrm{AChE}$ activity at Boron doped polycrystalline diamond electrode is based on the oxidation of thiocholine, the enzymatic reaction product of immobilized $\mathrm{AChE}$ in the presence of the substrate acetylthiocholine chlorid (ATCl) and this without the need to further modify the BDPD surface or the use of other reagents. The concentration of immobilized active AChE enzymes was estimated to $\Gamma \approx 1.810^{12} \mathrm{AChE}$ $\mathrm{cm}^{-2}$ by means of a calibration curve. Michaelis constant was assessed with a $\mathrm{Km}$ of 4.3 $10^{-4} \mathrm{M}$. Finally, the electrochemical quantification and detection of Malathion shows a good linear calibration curve where the concentration of Malathion range is from 2 to 6 $\mathrm{nM}$ within 6 minutes after inhibitor addition.
\end{abstract}

\section{INTRODUCTION}

Organophosphates (OPs) are most typically used pesticides in agriculture and industry worldwide because of their high insecticidal activity. However, the poor control of the pesticides use has resulted in their introduction into water and food resources causing many poisonings [1] and killing over 100,000 people annually [2]. OPs compounds act as inhibitors of acetylcholinesterase enzyme (AChE) in the peripheral and central nervous systems [3]. AChE breaks down acetylcholine (ACh) neurotransmitter into choline and acetate preventing overstimulation and blockage of ACh receptors. When AChE is inhibited by OPs, ACh cannot be cleaved and it accumulated at the receptors leading to fatal disruptions of the nervous system [4, 5]. Therefore, the development of screening methods for identifying AChE inhibitors is a topic of substantial interest in the environmental, food, agricultural and biomedical domains [6, 7]. The use of AChE biosensors for the accurate identification and quantification of AChE inhibitors has been increased because they are sensitive, fast, cheap and portable they also allowed longer duration of enzyme activity, and multiple assays can be realized with eventual enzyme reactivation [8]. Furthermore, this biosensor can be used even in the detection of drugs for neurodegenerative diseases, particularly, Alzheimer's disease $[9,10]$. Electrochemical biosensors are powerful tools for the detection of OPs in real time, especially amperometric biosensors $[11,12]$. The activity of the enzyme is measured by the anodic oxidation of thiocholine, the product of the enzymatic reaction $[13,14]$. The inhibition of AChE by OPs was monitored by measuring the decrease of thiocholine anodic oxidation signal which is inversely proportional to the concentration of OPs pesticides. Many different amperometric biosensor designs exist for the purpose of detecting OPs featuring AChE enzyme as the biological recognition element coupled with a variety of transducers.

Porous silicon (PSi) material has been used as highperformance solid substrate due to their large surface to volume ratio which allowed the attachment of a large number of molecules over a large surface in a small volume [15, 16]. In addition, PSi is easily prepared either in powder [17] or wafer [18], it has an excellent biocompatibility [19] and has flexibility in controlling the surface chemistry [20,21] which make this material ideal for the immobilization of enzymes [22]. However, PSi amperometric biosensors didn't get much attention most likely due its low conductivity and weak stability [23]. As it well known, in electrochemical biosensors the transductor must have high conductivity, robust stability, a large and effective electrochemical area, and good cycling performance. In this framework, several methods were reported to enhance the conductivity and the stability of PSi surface by molecule grafting or by deposition of conductive materials [24-27]. However, this is not enough, as once the enzymes are immobilized on these modified surfaces; the conductivity will decrease again, which calls for new solutions. By contrast Boron doped diamond (BDD) electrode has 
exceptional electrochemical properties: - Very high chemical stability - A large electroactivity window (approximately 3.5 $\mathrm{V}$ in aqueous solution), the reactions occurring in potentials ranging from about $-0.5 \mathrm{~V}$ to $-1.2 \mathrm{~V}$ and from $1.8 \mathrm{~V}$ to about $2.5 \mathrm{~V}$ can be analyzed which could not be analyzed on traditional electrode surfaces such as Au and Pt [28, 29] - Low residual current density which allows higher sensitivity and low detection limits. The use of BDPD electrode for the electrochemical measurements could overcome the problem of PSi low conductivity. The combination between BDPD as electrode to record the electrochemical response and PSi as a matrix for enzyme immobilization seems then a good choice to construct high-quality amperometric biosensors. Parsajoo et al. [30] have reported a similar tool using chemically linked AChE onto a gold disk substrate adjacent to a silver disk amperometric working electrode. For practical purposes, a direct quantification of the number of active immobilized enzymes is needed. Various biomonitoring methods have been developed and proposed for this purpose. Most of them rely on the colorimetric assay commonly called as the Ellman's method [31-33]. A few other methods, which use Fouriertransform infrared spectrometry [34], surface plasmon resonance [35] and fluorescence assay [36]. Although there are many papers that discus electrochemical biosensor based on enzymes immobilization, just few of them dealt with counting the number of active immobilized enzymes [37-39].

In the present study, effective and nontoxic analytical approach was developed to measure the total amount of active and inhibited immobilized AChE and to detect Malathion, an AChE inhibitor in real time by electrochemical oxidization of thiocholine. For this purpose, PSi surface was used for the covalent immobilization of $\mathrm{AChE}$ and a BDPD working electrode for thiocholine detection. According to our knowledge, there is no such report in the literature up to now. This method allowed the determination of kinetic parameters of the enzymatic reaction as well.

The next section (section 2) presents the different products and materiels exploited during this work, the protocols for the synthesis of electrodes and procedures for the various electrochemical measurments. The third section, entitled results and discussions, concerns the interpretation and explanation of the obtaned results. We finish with section 4 where we report the conclusions drawn from this work.

\section{EXPERIMENTAL SECTION}

\subsection{Materials}

Silicon wafers (double side polished, (100)-oriented, borondoped p-type, and resistivity of $0.08-0.12 \Omega \mathrm{cm}$ ) were purchased from Siltronix, France. Boron doped polycrystalline diamond (BDPD) was developed at the Institute of Electronics, Microelectronics and Nanotechnology (IEMN), CNRS - 8520, Villeneuve d'Ascq, France. BDPD films (1.5-2.0 $\mu \mathrm{m}$ thick) were deposited on silicon substrates. The level of boron doping is in the range of $10^{19}-10^{20} \mathrm{~B} \mathrm{~cm}^{-3}$ assessed by SIMS measurements.

Gold chloride $\left(\mathrm{HAuCl}_{4}, 47.8 \%\right)$, AChE from Electrophorus electricus (E.C. 3.1.1.7, $265 \mathrm{U} \mathrm{mg}^{-1}$ ), acetylthiocholinechlorid (ATCl), organosilane reagent 3-aminopropyltriethoxysilane (APTES), and the chemicals carbodiimide N-ethyl-N'-(3dimethylaminopropyl)- carbodiimide (EDC) ( 98\%) and Nhydroxysuccinimide (NHS) were purchased from Sigma. All cleaning (hydrogen peroxide 30\%; sulfuric acid 96\%; acetic acid 100\%) and etching Fluorhydric acid (HF) $50 \%$ reagents were of VLSI grade and supplied by Carlo Erba. Deionized (DI) water was used for the preparation of the solutions and rinses. 10X Phosphate Buffer Solution (PBS, $\mathrm{pH}=7.4$ ) was obtained from Ambion.

\subsection{Substrate preparation}

Silicon wafers were cut into $15 \times 15 \mathrm{~mm}^{2}$ sized samples and cleaned in $1 / 3(\mathrm{v} / \mathrm{v}) \mathrm{H}_{2} \mathrm{O}_{2} / \mathrm{H}_{2} \mathrm{SO}_{4}$ piranha solution for $15 \mathrm{~min}$ at $100^{\circ} \mathrm{C}$ and copiously rinsed with DI water. The native oxide was removed by immersing the samples in $47 \%$ aqueous $\mathrm{HF}$ for 30s. PSi layers were prepared by wet electrochemical etching of the hydrogen-terminated surfaces in a $1 / 1(\mathrm{v} / \mathrm{v}) 47 \%$ $\mathrm{HF} / \mathrm{absolute}$ ethanol mixture for $30 \mathrm{~s}$ at a current density of 80 $\mathrm{mA} \mathrm{cm}{ }^{2}$.

\subsection{Acetylcholinesterase immobilization}

Prior to enzyme immobilization, gold nanoparticles were deposited into PSi surface by electroless plating. A drop of 50 $\mu \mathrm{l}$ of $1 \% \mathrm{HAuCl}_{4}$ solution (prepared in $\mathrm{HF}$ ) was deposited onto the freshly prepared PSi surface for $1 \mathrm{~min}$. Au ions are reduced by Si-H bonds leading to the decoration of PSi surface with $\mathrm{Au}$ particles (PSi-AuNP). The sample was thoroughly rinsed with deionized water and well dried under nitrogen stream. The resulting PSi-AuNP surface was oxidized at $200{ }^{\circ} \mathrm{C}$ for $30 \mathrm{~min}$ to form -OH bonds required for the grafting of APTES precursor. Subsequently, the substrate was immersed in a solution of 3\% (v/v) APTES in $95 \%(\mathrm{v} / \mathrm{v})$ ethanol for $2 \mathrm{~h}$ at room temperature. The sample was then flushed with ethanol to remove non-covalently bound APTES, and was cured at $80^{\circ} \mathrm{C}$ for $20 \mathrm{~min}$. The contact angle measurements of the resulting PSi-AuNP-NH 2 surface were found to be about $10^{\circ}$. This value is less than that obtained for $\mathrm{PSi}-\mathrm{NH}_{2}$ surface $\left(40^{\circ}\right)$ [33], indicating that the presence of AuNP on the PSi surface decreased the surface hydrophobicity. The surface now bearing $\mathrm{NH}_{2}$ end groups was hence used for the covalent linking of AChE. The PSi-AuNP-NH $\mathrm{N}_{2}$ surface was introduced in a solution mixture of $0.08 \mu \mathrm{M}$ AChE, $5 \mathrm{mM}$ EDC and $5 \mathrm{mM}$ NHS in PBS aqueous solution (this mixture was previously left to react for two hours at $15^{\circ} \mathrm{C}$ ) and allowed to react overnight at room temperature. The resulting surface was copiously rinsed with DI water and dried under a nitrogen stream. The PSi-AuNP-NH-AChE interface was stored at $4{ }^{\circ} \mathrm{C}$ before use.

\subsection{SEM observations}

Scanning electron microscope (SEM) images were recorded by Philips scanning electron microscope.

\subsection{Electrochemical measurements}

Electrochemical measurements were performed in ambient temperature using a potentiostat BioLogique Science Instrument equipped with the software EC-Lab Express. The electrochemical cell used comprises three electrodes: platinum counter electrode, $\mathrm{Ag} / \mathrm{AgCl}$ reference electrode and BDPD working electrode. The voltammograms were recorded with a scan rate of $50 \mathrm{mV} / \mathrm{s}$.

\subsubsection{Calibration curve}

Calibration curve is used to estimate the concentration of 
active enzyme on the modified PSi surface. First, stock solution of ATCl $(0.1 \mathrm{M})$ and solutions with different concentrations of AChE enzyme were prepared in 1X PBS. An amount of AChE (for each concentration) was poured into a test tube containing $30 \mu \mathrm{l}$ of ATCl stock solution and 1X PBS buffer solution was added to reach a final volume of $3 \mathrm{ml}$. The obtained ATCl concentration is $0.33 \mathrm{mM}$ and $\mathrm{AChE}$ concentrations are $\mathrm{C} 1=0.0026 \mu \mathrm{M}, \mathrm{C} 2=0.0052 \mu \mathrm{M}, \mathrm{C} 3=$ $0.0079 \mu \mathrm{M}, \mathrm{C} 4=0.010 \mu \mathrm{M}, \mathrm{C} 5=0.013 \mu \mathrm{M}$. After $10 \mathrm{~min}$ reaction, the mixture is transferred in the electrochemical cell to record the cyclic voltammograms.

\subsubsection{Activity of immobilized AChE}

To assess the activity of immobilized enzyme, PSi-AuNP$\mathrm{NH}-\mathrm{AChE}$ surface was immersed in $30 \mu \mathrm{l}$ of ATCl solution (0.33 $\mathrm{mM}$ in PBS) and allowed to incubate for $10 \mathrm{~min}$. Then the surface was removed, and the voltammogram was recorded at BDPD electrode.

\subsubsection{Michaelis-Menten constants measurements}

PSi-AuNP-NH-AChE surface was incubated for $20 \mathrm{~min}$ in ATCl solutions with different concentrations $(\mathrm{C} 1=0.125 \mathrm{mM}$, $\mathrm{C} 2=0.254 \mathrm{mM}, \mathrm{C} 3=0.375 \mathrm{mM}, \mathrm{C} 4=0.5 \mathrm{mM}, \mathrm{C} 5=0.625 \mathrm{mM})$. The sample was removed and the solution mixture of each concentration was poured into the electrochemical cell to record the cyclic voltammograms at BDPD electrode.

\subsubsection{Inhibition}

To assess Malathion inhibition, PSi-AuNP-NH-AChE sample was first immersed for 6 min in Malathion solutions of different concentrations (from 2 to $6 \mathrm{nM}$ ). The sample was profusely rinsed with deionized water and transferred into a test tube containing $4 \mathrm{ml}$ of ATCl solution $(0.55 \mathrm{mM})$. After 20 min reaction, the sample was removed from the tube and the solution was poured into the electrochemical cell to study the electrochemical response at BDPD electrode by cyclic voltammetry.

\subsubsection{Reactivation enzyme}

After exposure of the SiP-NPAu-NH-AChE electrode to Malathion, it was washed with $0.1 \mathrm{M}$ phosphate buffer $(\mathrm{pH} 7.5$ ) and reactivated with $4.0 \mathrm{mM}$ 2-pyridine aldoxime methiodide [2-PAM] for $20 \mathrm{~min}$.

\section{RESULTS AND DISCUSSION}

\subsection{SEM observation of the mesoporous silicon formation}

The formation of mesooporous silicon is confirmed by the SEM micrograph of the surface (Figure 1.a) which shows an average pore size of $20-30 \mathrm{~nm}$. The porous surface is homogeneous with a uniform pore distribution. The thickness of the porous layer was determined by observation of the cleavage sample (Figure 1.b). This last reveals the spongy morphology of the obtained mesoporous silicon. The porous layer is regular with a thickness of $3.2 \mu \mathrm{m}$.

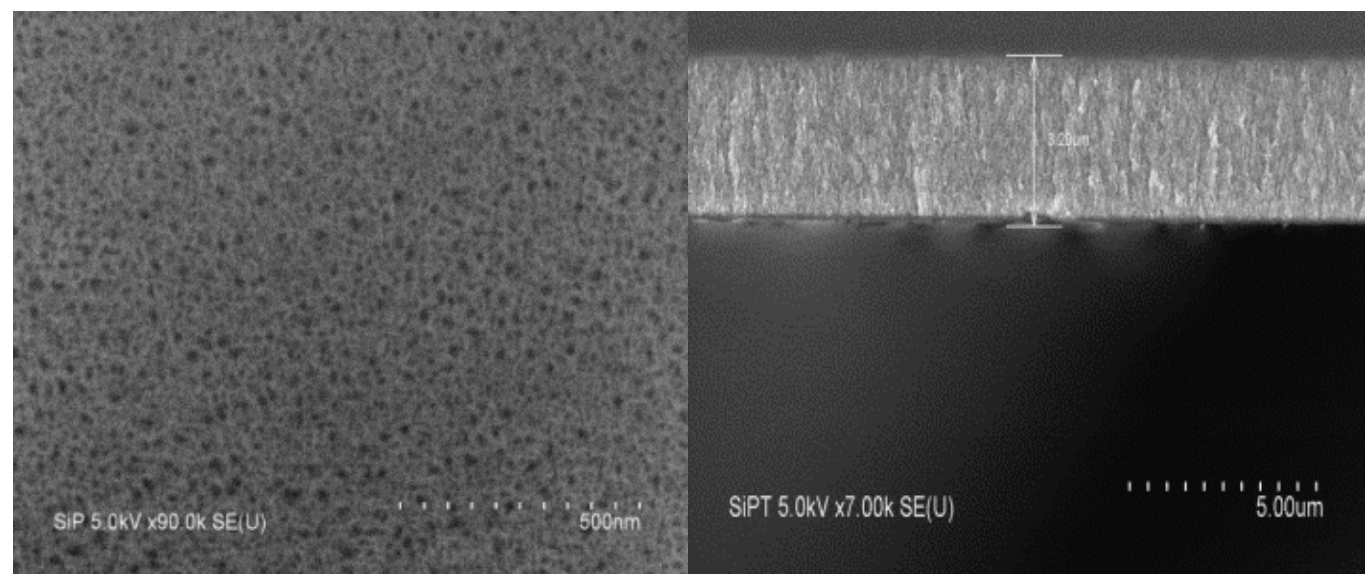

(a)

(b)

Figure 1. SEM micrographs of the mesoporous silicon: (a) surface view and (b) side view

\subsection{Comparison between the two electrodes PSi-AuNP- NH-AChE and BDPD}

The electrochemical stability of PSi-AuNP-NH-AChE and BDPD electrodes was tested by recording successive cyclic voltammograms at a scan rate of $50 \mathrm{mV} \mathrm{s}^{-1}$ in a solution containing only PBS 1X (Figure 2). We can observe in the Figure 2.a the non-stability of the PSi-AuNP-NH-AChE electrode. The current intensity decreases after each scan due to the surface oxidation. In fact, the remaining $\mathrm{Si}-\mathrm{H}$ bonds onto the PSi surface are oxidized after each cycle, which increases the resistivity of the surface.

In contrast, the Figure 2.b shows that BDPD electrode is more stable. The obtained voltammograms maintain the same shape over several cycles and no loss of current intensity was observed.
The electrochemical response of PSi-AuNP-NH-AChE and BDPD electrodes in the presence of AChE (13 nM) and its substrate ATCl $(0.33 \mathrm{mM})$ was also inspected in PBS 1X solution.

The cyclic voltammorgrams depicted in Figure 3 were recorded after 5 min enzymatic reaction where AChE enzyme catalyzes the hydrolysis of ATCl and produces thiocholine [13, 14] as shown in reaction 1 :

$$
\text { Acetylthiocholine }+\mathrm{H}_{2} \mathrm{O} \stackrel{A C h E}{\longrightarrow} \text { thiocholine }+ \text { acetic acid }
$$

The enzymatic reaction product thiocholine is prone to oxidation according to the reaction 2 :

$$
2 \text { thiocholine } \rightarrow \text { disulfide }+2 \mathrm{H}^{+}+2 \mathrm{e}^{-}
$$


No anodic peak is observed in the curve PSi-AuNP-NHAChE (Figure 3) indicating that the oxidation of thiocholine on PSi-AuNP-NH-AChE electrode does not occur. Whilst, the voltammetric curve BDPD (Figure 3) exhibits an anodic peak at $1 \mathrm{~V}$ corresponding to the oxidation of thiocholine on the BDPD electrode.
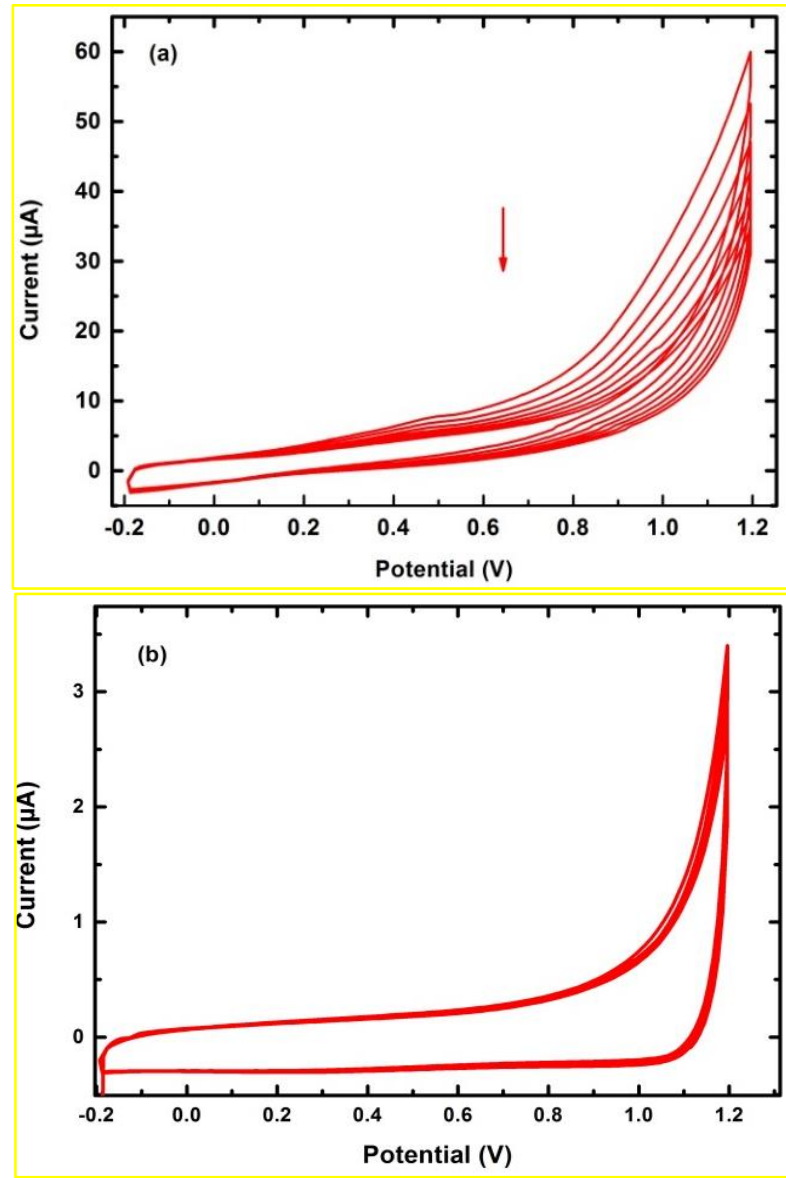

Figure 2. Successive cyclic voltammograms in PBS $1 \mathrm{X}$ at: a) PSi-AuNP-NH-AChE electrode and b) BDPD electrode. Scan rate $50=\mathrm{mV} \mathrm{s}^{-1}$

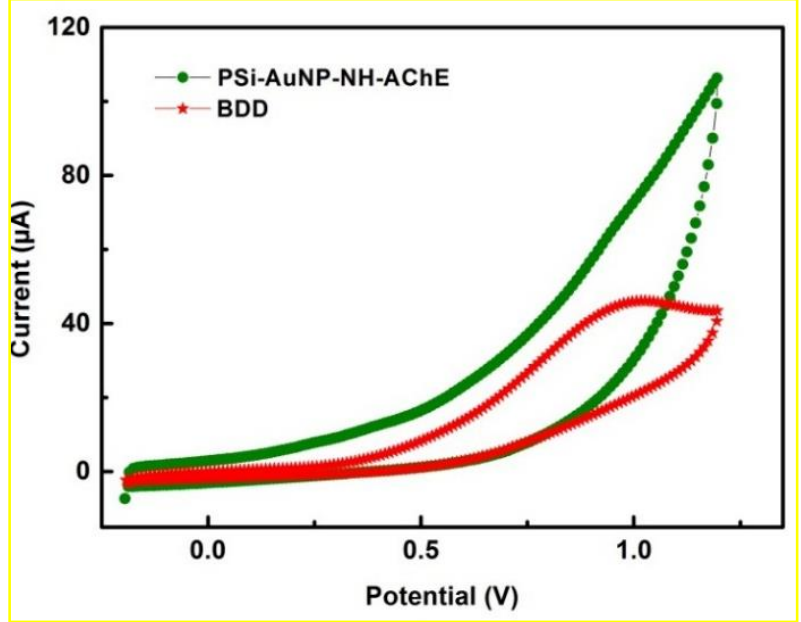

Figure 3. Electrochemical response of PSi-AuNP-NH-AChE and BDPD electrodes in PBS $1 \mathrm{X}$ solution containing AChE

$(13 \mathrm{nM})$ and $\mathrm{ATCl}(0.33 \mathrm{mM})$. Scan rate $50=\mathrm{mV} \mathrm{s}^{-1}$

These results indicate that the PSi-AuNP-NH-AChE electrode is inert and it cannot be used for the electrochemical detection of AChE enzyme activity or inhibition. BDPD electrode seems to be more suitable for the electrochemical assays due to its stability and its electrochemical activity.

\subsection{Calibration curve of free $\mathrm{AChE}$}

To determine the concentration of active enzyme after immobilization, a calibration curve in solution was established. It represents the oxidation peak intensity of thiocholine at BDPD electrode versus the concentration of free AChE in solution. Figure 4.a shows the voltammograms obtained for different concentrations of $\mathrm{AChE}$ enzyme in the presence of $0.33 \mathrm{mM}$ ATCl. The presence of enzymatic activity is evidenced by the observation of the anodic peak at $1 \mathrm{~V}$ indicating the oxidation of the formed thiocholine during the enzymatic reaction. The anodic current intensity evolves linearly with AChE amount in solution (Figure 4.b). This calibration curve is used to assess the concentration of immobilized active AChE on PSi surface.
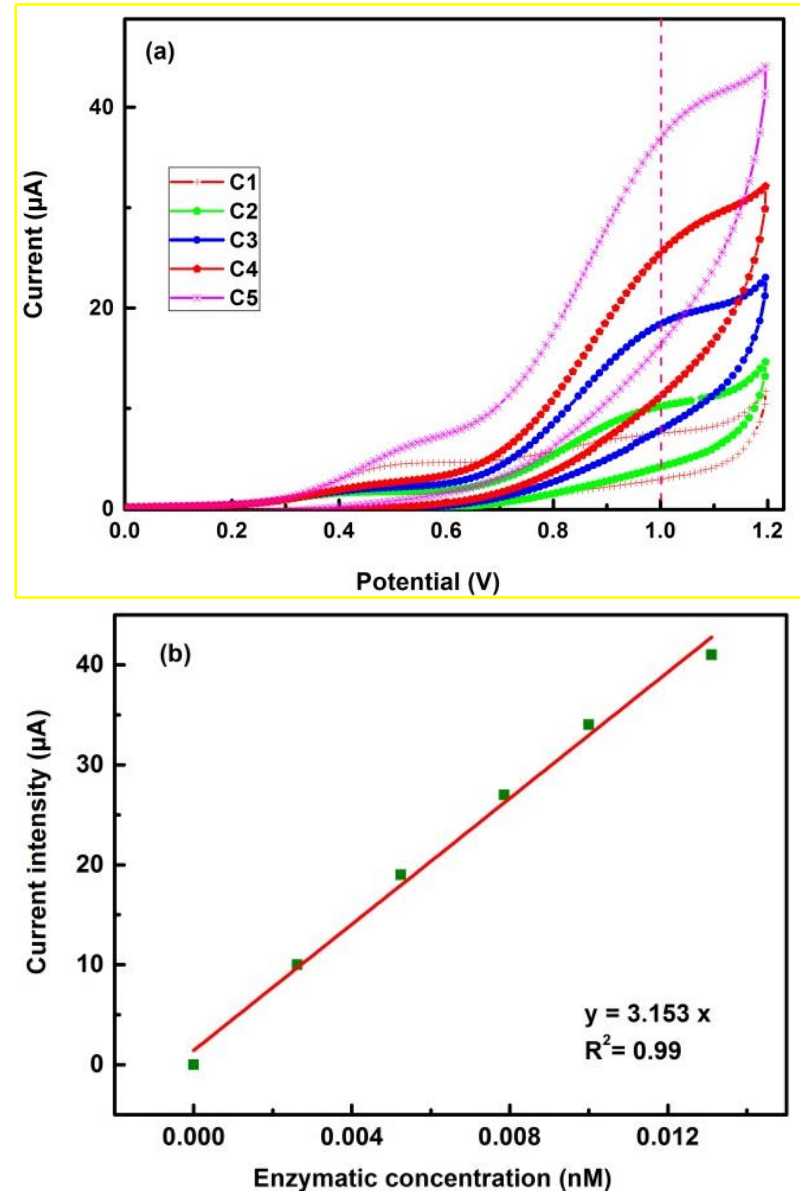

Figure 4. a) Cyclic voltammograms at BDPD electrode of AChE solution with different concentrations $(\mathrm{C} 1=2.62 \mathrm{nM}$, $\mathrm{C} 2=5.24 \mathrm{nM}, \mathrm{C} 3=7.86 \mathrm{nM}, \mathrm{C} 4=10 \mathrm{nM}, \mathrm{C}=13.1 \mathrm{nM})$ in the presence of $0.33 \mathrm{mM}$ ATCl. Scan rate $50=\mathrm{mV} \mathrm{s}^{-1}$. b) The calibration curve of the current intensity as a function of the AChE concentrations

\subsection{Enzyme activity assessment of immobilized AChE}

Figure 5 depicts the cyclic voltammogram at BDPD electrode of $0.33 \mathrm{mM}$ ATCl solution in which PSi-AuNP-NH$\mathrm{AChE}$ surface was previously incubated for $10 \mathrm{~min}$. Prior to electrochemical measurements, the sample was removed and 
the solution mixture was poured in the electrochemical cell. The activity of immobilized AChE enzyme on PSi-AuNP-NHAChE surface was evidenced by the arising of an anodic peak at $0.7 \mathrm{~V}$ corresponding to the oxidation of thiocholine.

The value of the oxidation peak intensity is $2.4 \mu \mathrm{A}$ and according to the calibration curve previously established (Figure 4.b), the surface concentration of active enzymes was estimated to be $\Gamma \approx 1.8 \times 10^{12} \mathrm{AChE} . \mathrm{cm}^{-2}$. This value is higher than the value obtained in our previous work [33], where the enzyme immobilization was done on $\mathrm{SiP}-\mathrm{NH}_{2}$ surface i.e. without $\mathrm{Au}$ deposition. It seems that gold nanoparticles decrease the surface hydrophobicity leading to a favorable orientation of the enzyme on the surface i.e. active sites are oriented outwards.

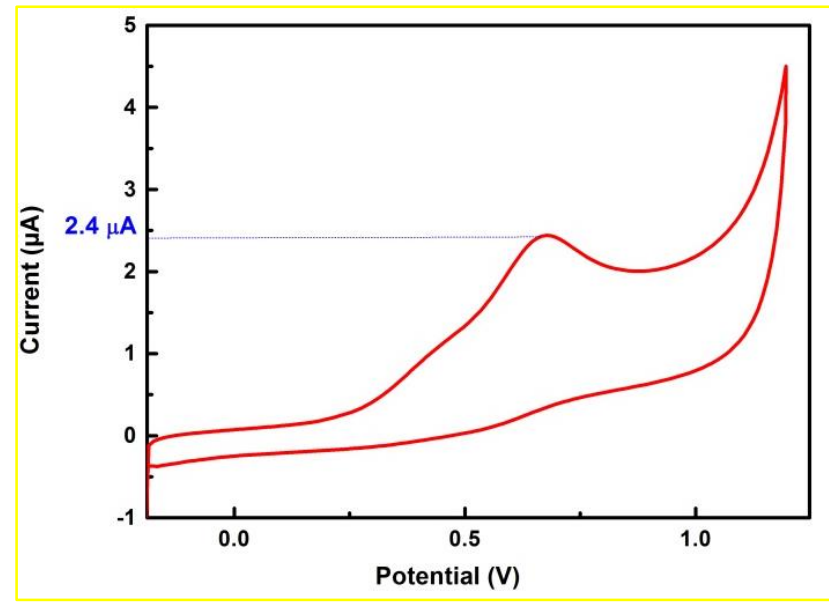

Figure 5. Cyclic voltammogram at BDPD electrode of $0.33 \mathrm{mM}$ ATCl solution in which PSi-AuNP-NH-AChE surface was incubated for $10 \mathrm{~min}$. Scan rate $50=\mathrm{mV} \mathrm{s}^{-1}$

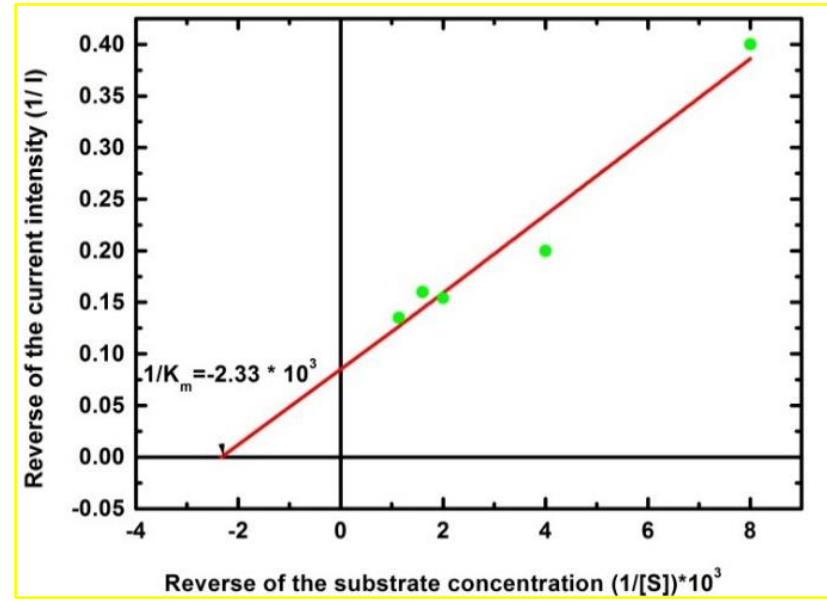

Figure 6. Lineweaver and Burk representation of the enzymatic reaction at different $\mathrm{ATCl}$ substrate concentrations

To study the kinetics of the enzymatic reaction, cyclic voltammorgrams were recorded at BDPD electrode in ATCl solutions with different concentrations $(\mathrm{C} 1=0.125 \mathrm{mM}$, $\mathrm{C} 2=0.254 \mathrm{mM}, \mathrm{C} 3=0.375 \mathrm{mM}, \mathrm{C} 4=0.5 \mathrm{mM}, \mathrm{C} 5=0.625 \mathrm{mM}$ ) in which PSi-AuNP-NH-AChE surface was previously incubated for $20 \mathrm{~min}$. The intensity of the anodic peak at 0.7 $\mathrm{V}$ increases when ATCl concentration increases. Lineweaver and Burk curve $(1 / \mathrm{i}=\mathrm{f}(1 /[\mathrm{S}])$ depicted in Figure 6 allowed to determine Michaelis constant $(\mathrm{Km})$ corresponding to the substrate concentration [S] for which the enzymatic catalysis occurs with half of its maximum velocity. $\mathrm{Km}$ value assessed from this representation is $0.43 \mathrm{mM}$. This value is higher than the value $0.258 \mathrm{mM}$ obtained with Mahmoudi team [40] but smaller than $1.89 \mathrm{mM}$ obtained by the Cui team [41].

\subsection{Malathion detection}

In the presence of pesticides, the enzyme function is inhibited, resulting in a decrease in thiocholine formation. The inhibition degree of $\mathrm{AChE}$ is therefore correlated to the decrease in thiocholine oxidative current, which depends on the concentration of Malathion in the sample. To assess AChE inhibition by Malathion, PSi-AuNP-NH-AChE surface was first immersed for $6 \mathrm{~min}$ in Malathion solutions with different concentrations (from 2 to $6 \mathrm{nM}$ ), and then in $0.55 \mathrm{mM} \mathrm{ATCl}$ solution for $20 \mathrm{~min}$. The cyclic voltammograms were recorded at BDPD electrode in the ATCl solution in which the inhibited PSi-AuNP-NH-AChE surface was incubated. The results are depicted in the Figure 7. We observe in the inset figure the decrease of thiocholine oxidation peak intensity when Malathion concentration increases; indicating the inhibition of AChE enzyme. The inhibition was calculated as fellow:

$$
\text { Inhibition }(\%)=100 \times \frac{i_{p, \text { control }}-i_{p, \text { exp }}}{i_{p, \text { control }}}
$$

where,

$i_{p, \text { control }}$ is the current corresponding to the voltammetric response at BDPD electrode of ATCl solution in which PSiAuNP-NH-AChE surface was previously incubated without inhibitor.

$i_{p, \exp }$ is the current corresponding to the response at BDPD electrode of ATCl solution in which PSi-AuNP-NH-AChE surface was previously incubated in Malathion.

The calibration curve displayed in Figure 7 shows that the oxidation peak intensity increases linearly with Malathion concentration with a slope of 4.3 and $R^{2}$ of 0.99 . We note that the linearity is obtained for Malathion low concentrations making these structures useful for real applications.

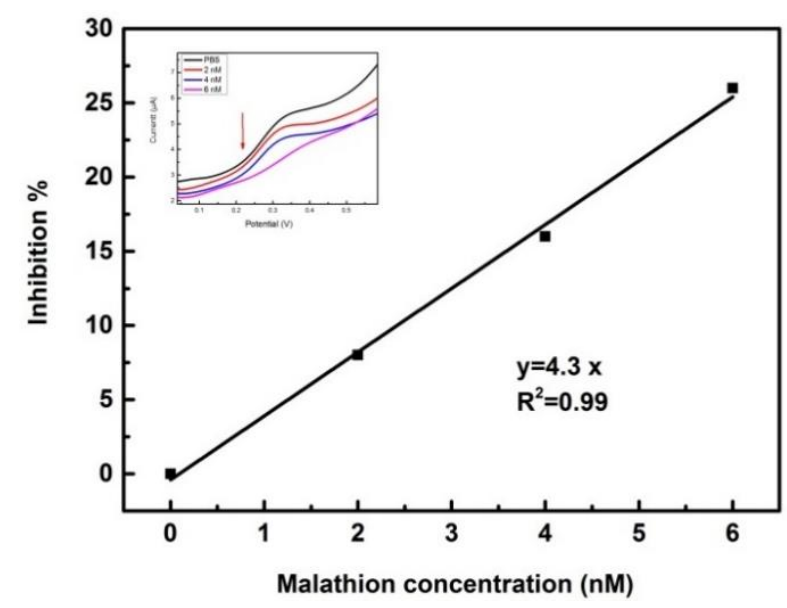

Figure 7. Calibration curve of AChE inhibition as a function of Malathion concentration

\section{CONCLUSIONS}

In this work, an electrochemical method for quantification of active immobilized enzymes (AChE) have been explored 
using BDPD electrode to record the electrochemical signal and PSi as matrix for AChE immobilization.

We have shown that BDPD electrode is more stable and more sensitive than PSi-AuNP-NH-AChE electrode for the electrochemical measurements.

Besides, the results confirmed that the deposited gold particles on the PSi surface create more favorable surface for the immobilization of AChE enzyme.

Using this strategy, we were able to assess:

(i) the total immobilized active AChE amount, the number of inhibited AChE can be measured by subtracting the active AChE (after inhibition) from the total amount, (ii) the quantification of AChE inhibitors (Malathion) and (iii) the Michaelis constant value of the enzymatic reaction.

The proposed method is simple, rapid, sensitive and inexpensive. The additional advantage that this method presente, is the good flexibility regarding the support and the working electrode, we can use different types of working electrodes such as graphite, carbon paste, gold, glassy carbon and so on as needed, likewise, other enzyme supports can be used even if they don't have good electrochemical properties as glass, nylon, clay, $\mathrm{SiO}_{2}, \mathrm{TiO}_{2}$ etc.... We can also find flexibility in the commercial design of the position of these two electrodes: adjacent, parallel or even use the working electrode as a grid on the modified support. According to all of the above, it can be said that a promising devices for OPs detection was developed and it can be beneficial in a number of industrial applications.

\section{ACKNOWLEDGEMENTS}

We are grateful to the financial support of the National Research Fund (DGRSDT).

\section{REFERENCES}

[1] Gupta, R.C., Miller Mukherjee, I.R., Malik, J.K., Doss, R.B., Dettbarn, W.D., Milatovic, D. (2019). Chapter 26 - insecticides. Biomarkers in Toxicology, 455-475. https://doi.org/10.1016/B978-0-12-814655-2.00026-8

[2] Eddleston, M. (2019). Novel clinical toxicology and pharmacology of organophosphorus insecticide selfpoisoning. Annual Review of Pharmacology and Toxicology, 59: 341-360. https://doi.org/10.1146/annurev-pharmtox-010818021842

[3] Jose Martin-Reina, J.A.D., Cerrillos, L., Bautista, J.D., Soliman, M.M. (2017). Insecticide reproductive toxicity profile: organophosphate, carbamate and pyrethroids. Journal of Toxins, 4: 7. https://doi.org/10.13188/23281723.1000019

[4] De Bleecker, J.L. (2008). Organophosphate and carbamate poisoning. Handbook of Clinical Neurology, 91: 401-432. https://doi.org/10.1016/S00729752(07)01513-8

[5] Pearson-Smith, J.N., Patel, M. (2020). Antioxidant drug therapy as a neuroprotective countermeasure of nerve agent toxicity. Neurobiology of Disease, 133: 104457. https://doi.org/10.1016/j.nbd.2019.04.013

[6] Nicolopoulou-Stamati, P., Maipas, S., Kotampasi, C., Stamatis, P., Hens, L. (2016). Chemical pesticides and human health: The urgent need for a new concept in agriculture. Frontiers in Public Health, 4: 148. https://doi.org/10.3389/fpubh.2016.00148

[7] Arduini, F., Amine, A., Moscone, D., Palleschi, G. (2010). Biosensors based on cholinesterase inhibition for insecticides, nerve agents and aflatoxin B 1 detection. Microchimica Acta, 170: 193-214. https://doi.org/10.1007/s00604-010-0317-1

[8] Spahn, C., Minteer, S.D. (2008). Enzyme immobilization in biotechnology. Recent Patents on Engineering, 2: 195200. https://doi.org/10.2174/187221208786306333

[9] El Harrad, L., Bourais, I., Mohammadi, H., Amine, A. (2018). Recent advances in electrochemical biosensors based on enzyme inhibition for clinical and pharmaceutical applications. Sensors, 18: 164. https://doi.org/10.3390/s18010164

[10] Shamagsumova, R.V., Yu Efimova, O., Gorbatchuk, V.V., Evtugyn, V.G., Stoikov, I.I., Evtugyn, G.A. (2019). Electrochemical acetylcholinesterase biosensor based on polylactide-nanosilver composite for the determination of anti-dementia drugs. Analytical Letters, 52: 15581578. https://doi.org/10.1080/00032719.2018.1557202

[11] Zhang, P., Sun, T., Rong, S., Zeng, D., Yu, H., Zhang, Z., Chang, D., Pan, H. (2019). A sensitive amperometric AChE-biosensor for organophosphate pesticides detection based on conjugated polymer and Ag-rGO$\mathrm{NH}_{2}$ nanocomposite. Bioelectrochemistry, 127: 163-170. https://doi.org/10.1016/j.bioelechem.2019.02.003

[12] Hou, W., Zhang, Q., Dong, H., Li, F., Zhang, Y., Guo, Y., Sun, X. (2019). Acetylcholinesterase biosensor modified with ATO/OMC for detecting organophosphorus pesticides. New Journal of Chemistry, 43: 946-952. https://doi.org/10.1039/C8NJ03429J

[13] Dong, J., Fan, X., Qiao, F., Ai, S., Xin, H. (2013). A novel protocol for ultra-trace detection of pesticides: Combined electrochemical reduction of Ellman's reagent with acetylcholinesterase inhibition. Analytica Chimica Acta, 761: 78-83. https://doi.org/10.1016/j.aca.2012.11.042

[14] Du, D., Ding, J., Tao, Y., Chen, X. (2008). Application of chemisorption/desorption process of thiocholine for pesticide detection based on acetylcholinesterase biosensor. Sensors and Actuators B: Chemical, 134: 908912. https://doi.org/10.1016/j.snb.2008.06.040

[15] Buriak, J.M. (2006). High surface area silicon materials: fundamentals and new technology. Philosophical Transactions of the Royal Society A: Mathematical, Physical and Engineering Sciences, 364: 217. https://doi.org/10.1098/rsta.2005.1681

[16] Lachenani, H., Larabi, A., Gabouze, N. (2019). Study of structural, electronic and vibrational properties of porous silicon with different porosity. Silicon, 11: 2505-2515. https://doi.org/10.1007/s 12633-019-00219-0

[17] Osminkina, L.A., Nikolaev, A.L., Sviridov, A.P., Andronova, N.V., Tamarov, K.P., Gongalsky, M.B., Kudryavtsev, A.A., Treshalina, H.M., Timoshenko, V.Y. (2015). Porous silicon nanoparticles as efficient sensitizers for sonodynamic therapy of cancer. Microporous and Mesoporous Materials, 210: 169-175. https://doi.org/10.1016/j.micromeso.2015.02.037

[18] Xu, J., Liu, S., Yang, Y., Li, J., Tian, C., Guo, L., Zhang, S., Liu, Y., Zhong, Z. (2019). Preparation of porous silicon by electrochemical etching methods and its morphological and optical properties. Int. J. Electrochem. Sci., 14, 5188-5199. https://doi.org/10.20964/2019.06.10 
[19] Zhang, D.X., Yoshikawa, C., Welch, N.G., Pasic, P., Thissen, H., Voelcker, N.H. (2019). Spatially controlled surface modification of porous silicon for sustained drug delivery applications. Scientific Reports, 9: 1367. https://doi.org/10.1038/s41598-018-37750-w

[20] Kilian, K.A., Bocking, T., Gooding, J.J. (2009). The importance of surface chemistry in mesoporous materials: Lessons from porous silicon biosensors. Chemical Communications, 630-640. https://doi.org/10.1039/b815449j

[21] Tieu, T., Alba, M., Elnathan, R., Cifuentes-Rius, A., Voelcker, N.H. (2019) Advances in porous silicon-based nanomaterials for diagnostic and therapeutic applications. Advanced Therapeutics, 2: 1800095. https://doi.org/10.1002/adtp.201800095

[22] Daneshjou, S., Dabirmanesh, B., Rahimi, F., Khajeh, K. (2017). Porous silicon nanoparticle as a stabilizing support for chondroitinase. International Journal of Biological Macromolecules, 94: 852-858. https://doi.org/10.1016/j.ijbiomac.2016.10.077

[23] Setzu, S., Monduzzi, M., Mula, G., Salis, A. (2011). Porous silicon-based electrochemical biosensors. Emerging Materials and Applications. http://dx.doi.org/10.5772/17068

[24] Guo, Y.Y., Su, S., Wei, X.P., Zhong, Y.L., Su, Y.Y., Huang, Q., Fan, C.H., He, Y. (2013). A silicon-based electrochemical sensor for highly sensitive, specific, label-free and real-time DNA detection. Nanotechnology, 24(44): 444012. https://doi.org/10.1088/09574484/24/44/444012

[25] Ressine, A., Vaz-Domínguez, C., Fernandez, V.M., De Lacey, A.L., Laurell, T., Ruzgas, T., Shleev, S. (2010). Bioelectrochemical studies of azurin and laccase confined in three-dimensional chips based on goldmodified nano-/microstructured silicon. Biosensors and Bioelectronics, 25(5): 1001-1007. https://doi.org/10.1016/j.bios.2009.09.014

[26] Ensafi, A.A., Abarghoui, M.M., Rezaei, B. (2014). Electrochemical determination of hydrogen peroxide using copper/porous silicon based non-enzymatic sensor. Sensors and Actuators B: Chemical, 196: 398405.https://doi.org/10.1016/j.snb.2014.02.028

[27] Ensafi, A.A., Abarghoui, M.M., Rezaei, B. (2014). A new electrochemical sensor based on porous silicon supported Pt-Pd nanoalloy for simultaneous determination of adenine and guanine. Sensors and Actuators B: Chemical, 204: 528-535. https://doi.org/10.1016/j.snb.2014.08.009

[28] Swain, G.M., Anderson, A.B., Angus, J.C. (1998). Applications of diamond thin films in electrochemistry. MRS Bulletin, 23(9): 56-60. https://doi.org/10.1557/s0883769400029389

[29] Panizza, M., Cerisola, G. (2005). Application of diamond electrodes to electrochemical processes. Electrochimica Acta, 51(2): 191-199. https://doi.org/10.1016/j.electacta.2005.04.023

[30] Parsajoo, C., Kauffmann, J.M. (2013). Development of an acetylcholinesterase immobilized flow through amperometric detector based on thiocholine detection at a silver electrode. Talanta, 109: 116-120. https://doi.org/10.1016/j.talanta.2013.01.062

[31] Worek, F., Eyer, P., Thiermann, H. (2012). Determination of acetylcholinesterase activity by the
Ellman assay: A versatile tool for in vitro research on medical countermeasures against organophosphate poisoning. Drug Testing and Analysis, 4(3-4): 282-291. https://doi.org/10.1002/dta.337

[32] Ellman, G.L., Courtney, K.D., Andres, V., Featherstone, R.M. (1961). A new and rapid colorimetric determination of acetylcholinesterase activity. Biochemical Pharmacology, 7(2): 88-95. https://doi.org/10.1016/0006-2952(61)90145-9

[33] Khaldi, K., Sam, S., Lounas, A., Yaddaden, C., Gabouze, N.E. (2017). Comparative investigation of two methods for Acetylcholinesterase enzyme immobilization on modified porous silicon. Applied Surface Science, 421(Part A): 148-154. https://doi.org/10.1016/j.apsusc.2016.12.169

[34] Khaldi, K., Sam, S., Gouget-Laemmel, A., Henry de Villeneuve, C., Moraillon, A., Ozanam, F., Yang, J., Kermad, A., Ghellai, N., Gabouze, N. (2015). Active acetylcholinesterase immobilization on a functionalized silicon surface. Langmuir, 31: 8421-8428. https://doi.org/10.1021/acs.langmuir.5b01928

[35] Milkani, E., Lambert, C.R., McGimpsey, W.G. (2011). Direct detection of acetylcholinesterase inhibitor binding with an enzyme-based surface plasmon resonance sensor. Analytical Biochemistry, 408(2): 212-219. https://doi.org/10.1016/j.ab.2010.09.009

[36] Zhang, R.L., Liang, S.S., Jin, M., He, T., Zhang, Z.Q. (2017). Simple and sensitive fluorescence assay for acetylcholinesterase activity detection and inhibitor screening based on glutathione-capped gold nanoclusters. Sensors and Actuators B: Chemical, 253: 196-202. https://doi.org/10.1016/j.snb.2017.06.136

[37] Du, D., Wang, J., Wang, L., Lu, D., Smith, J.N., Timchalk, C., Lin, Y. (2011). Magnetic electrochemical sensing platform for biomonitoring of exposure to organophosphorus pesticides and nerve agents based on simultaneous measurement of total enzyme amount and enzyme activity. Analytical Chemistry, 83: 3770-3777. https://doi.org/10.1021/ac200217d

[38] Du, D., Wang, J., Wang, L., Lu, D., Lin, Y. (2012). Integrated lateral flow test strip with electrochemical sensor for quantification of phosphorylated cholinesterase: biomarker of exposure to organophosphorus agents. Analytical Chemistry, 84: 1380-1385. https://doi.org/10.1021/ac202391w

[39] Bergman, J., Wang, Y., Wigström, J., Cans, A.S. (2018). Counting the number of enzymes immobilized onto a nanoparticle-coated electrode. Analytical and Bioanalytical Chemistry, 410: 1775-1783. https://doi.org/10.1007/s00216-017-0829-1

[40] Mahmoudi, E., Fakhri, H., Hajian, A., Afkhami, A., Bagheri, H. (2019). High-performance electrochemical enzyme sensor for organophosphate pesticide detection using modified metal-organic framework sensing platforms. Bioelectrochemistry, 130: 107348. https://doi.org/10.1016/j.bioelechem.2019.107348

[41] Cui, H.F., Zhang, T.T., Lv, Q.Y., Song, X., Zhai, X.J., Wang, G.G. (2019). An acetylcholinesterase biosensor based on doping $\mathrm{Au}$ nanorod@ $\mathrm{SiO}_{2}$ nanoparticles into $\mathrm{TiO}_{2}$-chitosan hydrogel for detection of organophosphate pesticides. Biosensors and Bioelectronics, 141: 111452. https://doi.org/10.1016/j.bios.2019.111452 